\title{
A Study of the Effectiveness of Hydroponic Growing Vari- ables on Lactuca sativa var. capitata
}

\author{
Jacob Zajkowski ${ }^{1}$ and Whitney Short ${ }^{1}$ \\ ${ }^{1}$ Anthony Wayne High School, Whitehouse, OH, USA

\section{ABSTRACT}

Hydroponic growing in controlled environment horticulture has been an increasingly used method of produce production around the world. Its many methods integrate sustainability and growth efficiency through the control of climatic and system variables. This study investigated control variables that would produce and market a more effective lettuce (lactuca sativa. var capitata) crop. Three objectives determined: the comparison between the dimensions of deep water culture systems and the lettuce harvesting length, consumer and ICP spectrometry recognition of different post-harvest hydroponic nutrient concentration, and the preference of lettuce grown in different hydroponic nutrient concentrations. Through growing trials and consumer tests, it was found that the 14 gallon $(102 \times 50.8 \times 66 \mathrm{~cm})$ size deep water culture system produced lettuce with larger harvest-length; spectrometry recognition of lettuce crops grown in different nutrient levels was effective with 7 of the 12 nutrients elements showing sufficient results of concentration in concentrated lettuce. Consumer identification recognition was not successful with $40 \%$ of consumers unable to recognize any nutrient concentration level compared to two other varieties. Representing a diverse market audience, consumers determined that variety 127 (50\% regular concentration) was preferred as significant market influence of purchase. This research will impact future studies in effective small scale hydroponic growing and growers looking to expand knowledge of beneficial growth.

\section{Introduction}

Researching ways to produce crops year-round with minimal resources is becoming more relevant in todays agriculture industry. As the population quickly rises, hydroponics is the most efficient way to grow crops in a controlled setting (White, 2004). It allows growers to take advantage of all year growing, and not having to worry about weather or other setbacks. There are many hydroponic systems and mediums available, but only specific growing systems conditions assist small producers in growing productivity. According to the USDA, small farm designation (GCIF < $\$ 350,000$ ) makes up $89.6 \%$ of all production agriculture operations in the United States (USDA, 2019). Among the $21.5 \%$ of share crop production they make up, $8.1 \%$ of those farms specialize in vegetable and melon production. Small scale vegetable grower play a significant role in regional food production, especially in rural and suburban communities. This target business does not have access to productivity enabling technologies, current modernization applications, and research on commercialization development. The small changes made by growers is dependent on the market "niche" they produce, market, and sell too.

This study determines when Lactuca Sativa var. capitata is grown in different nutrient levels, will plant tissue analysis in ICP-spectrometry recognize different concentration nutrient levels of lettuce, and can consumers recognize the same nutrient levels through sensory processing techniques. It also studies when lettuce is grown in three different dimensions of deep-water culture hydroponic systems, which system will result in the largest harvesting length of lettuce. These experimental questions allowed for data collection that would give results on whether consumers would be able to determine different nutrient concentrations. Previous literature on the objectives above lacks manageable methods, compliance of regular agricultural operation budgets, and achievable objectives that not only for large commercial operations. This study of control variables in greenhouse production is not novel, but serves to be evidence 
based literature to small scale plant production and consumer perspective of lettuce crops. A common study structure on the hydroponic consumer markets is focused regionally, and on sellers. Market Analysis of Hydroponic Lettuce in the Nashville Region does not collect data on direct consumers, but wholesalers and restaurants (Huang, 2002). Although it provides excellent information for a potential grower, market analysis studies like these neither benefit someone outside of that region, or a grower reaching direct customers. Previous research on Brazilian grown organic vs conventional lettuce sensory evaluation, demonstrates the effectiveness of ranking different samples on certain characteristics to achieve a confirmation of different types of lettuces grown or that is preferred (Fontana, 2018). Asking consumers to identify factors such as green color, size, thickness of lettuce leaf or the leaf crispness or bitter taste will be the categories used in this study to determine nutrient concentration (Gilmour, 2018).

Hydroponics is the purest form of growing crops due to its controlled environmental factors and no need for pesticides, along with other non-needed chemicals to be sprayed on the plants (Sardare, 2013). Efficient growth in its purest form requires nutrients that supplement soil aspects. A test determining plant nitrogen content in wheat plants effect on plant quantity and structures has data that shows the importance of balanced nutrients for a valid approach to understanding growth efficiency (Roll). As one of the objectives determines different nutrient levels that consumers prefer, nutrient balance is important to maintain to prevent other physiological changes on a crop.

\section{Hydroponics}

Hydroponics is a production method of growing plants with nutrient solution other than soil. Most methods of growing hydroponically involve controlled environments, usually in greenhouses. The differences in system factors are the support systems and the ways of distributing water. Many variations have been developed over the past few years to the basic system. According to the University of Massachusetts AG Extension "Although it is possible to use hydroponics as outdoor crops, most of the production in the U.S. today is in greenhouses" (Bartok, 2017). Some common growing mediums used include beds and trays of water, nutrient film, sand/soil culture, and piping. Some advantages are higher yields of crops, growing in greater density, and the use of less water. Some disadvantages include a greater initial investment, more technical skill is needed to run the operation, and it might have higher electricity cost (Barbosa, 2015).

\section{Nutrient Chemistry and Makeup}

In a hydroponic cropping system, a plant uptakes nutrients through the roots that are suspended in a nutrient stock. Replacing soil fertility, the nutrient solution provides chemistry elements that are beneficial for plant growth and the overall health of the plant. Macro and micronutrients have strong interrelated relationships and cycles with the plants physiological function. Deficiencies are a common example of plant nutrition affecting plant health, and possible fruiting depending on the crop. Specific nutrients equip the plants cell to preform certain function in a growth cycle. Oxygen and hydrogen within a plant control cellular respiration in the form of a organic compound. Likewise, Potassium $(\mathrm{K})$ contributes to ion pump exchange through ATPases (Roberts, 2019). Whether one nutrient directly impacts cellular function, all 20 elements in a plant help convert chemical energy through photosynthesis and support the electron transport chain.

\section{Deep Water Culture System}

Deep water culture growing is one of two main growing techniques in the production hydroponics industry. Unlike, the nutrient film technique system (NFT), this system incorporates a recirculation of a water supply as plants are suspended between the nutrient stock and O2. Additionally, extensive filtration and regulations systems filter unwanted elements and maintain the $\mathrm{pH} / \mathrm{EC}$ levels within the production water system (Roberts, 2019). Vegetative crops 
are most suitable for growth within this system. Lettuce, basil, or any leafy green varieties are most common in this system for their 30-35 day growing cycles. Structural layout and engineering of deep-water culture systems have been designed for high tunnel greenhouses to indoor farms, where vertical layers are used with induced lighting (GarzaAlonso, 2019).

\section{Sensory and Marketing Importance}

Food science research and marketing industries have used human senses to appeal to the decision-making cognition of people. Using sensory, or the five senses that connect exterior body structure function to neurological thinking in the brain, helps researchers understand what consumers will prefer more. From snack products to vegetables, humans judge the edible goods in front of them by many standard affected by personality or environment. Marketing teams suggest that $87 \%$ of consumers are likely to purchase an item if 2 or more of the 5 senses are stimulated when in the presence of the given item (Harvard Business Review, 2019). Produce, unlike dry foods, has a lower rate of consumer satisfaction and selection due to the physiological changes that occurs with time. Factors of what specific populations like and can tell sensory differences between, play a role in what the market will produce for that populations demand.

It was hypothesized that consumers will not be able to recognize different concentrations, allowing growers to focus more on quantitative production, compared to the local visual appeal of the produce. The most effective dimensions of deep-water culture hydroponic systems was hypothesized to be system 3 containing 27 gallons. The purpose of this study was to understand what factors and variables in small-scale hydroponic production can lead to more growing success. This study impacts agriculture in Northwest Ohio by showing hydroponic farmers and businesses specific studies on system control in which they can use for their operation. The results gained will advance farmer knowledge in the hydroponic industry.

\section{Methods}

\section{Plant Cultivation}

Growth. Experiments took place in a glass house from September to December 2020 at Anthony Wayne High School research greenhouse. Salanova butterhead lettuce seeds were germinated for 2-3week in a high humidity germination chamber with a rockwool hydroponic medium. Seedlings were then selected and transferred into a nutrient film technique hydroponic system. Water temperature, greenhouse temperature/humidity, nutrient concentration was all maintained throughout trials. Glasshouse was maintained at 76 degree Fahrenheit with 55\% humidity. Water temperature was heated to 68 degrees Fahrenheit with the use of a 300W Submersible Thermostat. The full strength nutrition solution had the following composition: Total Nitrogen N 4.30\%, P2O5 9.30\%, K2O 35.00\%, Mg 3.9\%, B 200 mg/kg, Cu 105 mg/kg, Fe 2100 mg/kg, Mn 190 mg/kg, Mo 42 mg/kg, Zn 210 mg/kg. Hydroponic systems had a 600-800ppm nutrient concentration of calcium nitrate and hydro grow nutrient combination. A pH control meter keeps records of all systems data and was adjusted if it exceeded the 5-6 level. Water supply was continuously aerated using an air pump, covered to protect against light exposure, and activity renewed for proper concentration.

\section{Dimensions of Deep Water Culture Systems and The Lettuce Harvesting Length}

Dimensions and structure have the possibility of playing a large role in the growth of lettuce. Three different sized deep water culture systems were tested and can be concluded most effective by the data collected on mass, length, and linear density. Each system has a corresponding amount of plants per volume of each system. For every .75L/1 plant. After 7 weeks and growing plants using Plant Cultivation Methods, lettuce was harvested independently for each system. Each individual crop will be weighed for their mass, and measured for their length and recorded. 
Table 1. Deep water culture hydroponic systems specification.

\begin{tabular}{|c|c|c|c|}
\hline & System 1 & System 2 & System 3 \\
\hline Volume Capacity & 4.6 gallon & 14 gallon & 27 gallon \\
\hline Dimensions & $77.5 \times 51.1 \times 36.2 \mathrm{~cm}$ & $102 \times 50.8 \times 66 \mathrm{~cm}$ & $102 \times 75 \times 70 \mathrm{~cm}$ \\
\hline Plant Ratio & 6 & 19 & 36 \\
\hline
\end{tabular}

\section{Post-Harvest Consumer and ICP Spectrometry Recognition}

Three assembled 27-gallon deep water culture systems were used for lettuce cultivation. 50 plants were germinated and grown based on methods from Plant Cultivation section. Each hydroponic system contained a varied amount of nutrient concentration each coded as a specific variety coordinating with its respective concentration. The Researcher labeled the 3 tubs A,B,C and their variety number. With TUB A growing lettuce variety 598 having $150 \%$ of suggested concentration, TUB B growing variety 341 with normal concentration, and TUB C growing variety 271 with $50 \%$ suggested nutrient concentration.

Table 2. Hydroponic System Concentration Variety Codes.

\begin{tabular}{|c|c|c|}
\hline Tub A & Tub B & Tub C \\
\hline Variety 598 & Variety 341 & Variety 271 \\
\hline $150 \%$ Concentration & $100 \%$ concentration & $50 \%$ concentration \\
\hline $1200-1300$ PPM & $600-800$ PPM & $200-300$ PPM \\
\hline
\end{tabular}

\section{ICP-Spectrometry}

Plants grew and were maintained in hydroponic systems for seven weeks before harvesting. Each variety of lettuce was harvested and stored separately for testing. Randomized 50 leaves from each growing tub were selected and prepared for lyopilization. Selected samples were pulverized; freeze dried for plant tissue analysis through Integrated Coupled Plasma Spectrometry. Testing will specifically test for macronutrient and micronutrient trends between lettuce varieties. The variance of concentration will be based on the macronutrient (Figure 3) and micronutrient (Figure 4) suggests plant tissue concentration scale.

Table 3: Table of Average Macronutrient Concentration Percentages.

\begin{tabular}{|c|c|c|c|c|c|}
\hline \multicolumn{6}{|c|}{ Macronutrient Element Concentration Scale } \\
\hline & DEFICIENT & LOW & NORMAL & HIGH & EXCESSIVE \\
\hline (N) Nitrogen & & & $3.5<x<4.5$ & & \\
\hline (P) Phosphorus & & & $0.40<x<0.70$ & & \\
\hline (K) Potassium & & & $4.50<x<8.00$ & & \\
\hline (Ca) Calcium & & & $1.00<\mathrm{x}<1.80$ & & \\
\hline
\end{tabular}




\begin{tabular}{|c|c|c|c|}
\hline \multirow{2}{*}{ (Mg) Magnesium } & \multirow{5}{*}{ (S) Sulfur } & & $0.30<\mathrm{x}<0.70$ \\
& & $0.30<\mathrm{x}<0.50$ & \\
\hline
\end{tabular}

Table 4: Table of Average Micronutrients Concentration in PPM.

\begin{tabular}{|c|c|c|c|c|c|}
\hline \multicolumn{6}{|c|}{ Micronutrient Element Concentration Scale } \\
\hline & DEFICIENT & LOW & NORMAL & HIGH & EXCESSIVE \\
\hline (Mn) Manganese & & & $50<x<200$ & & \\
\hline (Cu) Copper & & & $5<x<15$ & & \\
\hline (Zn) Zinc & & & $25<x<75$ & & \\
\hline$(\mathrm{Fe})$ Iron & & & $50<x<150$ & & \\
\hline (B) Boron & & & $30<x<60$ & & \\
\hline (Na) Sodium & & & N/A & & \\
\hline
\end{tabular}

\section{Consumer Recognition}

Consumers were given a survey of questioning to determine if they could identify which varieties of lettuce correlated to either lettuce grown in either high, average, or low nutrients concentrations. Subjects were asked to use four sensory processing tools: taste, sight, smell, and touch to draw conclusions; however it was asked to only draw independent conclusions of lettuce nutrient concentration based on taste and sight. Participants were given characteristics in which to base their comparison decide off of. Thickness, size, green color were suggested for sight. Leaf crispness, bitter taste, and grass aroma were suggested for taste.

\section{Survey Length}

Consumer testing involved participants having a plate of 3 labeled lettuce varieties and documents indicating concept and instructions, along with survey questions. Consumers were given a maximum time of 15 minutes to complete the sensory testing; this avoids possible experiment error or survey fatigue.

\section{Focus Audience}

The study was designed to test the whole market of possible lettuce consumers covering people of all ages and backgrounds. Age of consumers tested were 15-55 years old. A minimum age of 15 year old is the threshold to intellectual capability of full sensory processing and identification. 55 years of age was the maximum age of consumer as 55+ age group shows increase regression of fully functioning senses that could cause possible error in the study. This study group contained community members from the Northwest Ohio region. The purpose of a specific and skillful test audience is to improve the effectiveness of the questions and clarify of result indicators.

\section{Question Selection}

Question selection and wording was crucial in order for subjects to directly understand their task and the sensory method to accomplish the goal. Each question was asked separately to avoid the influence of previous and future 
observations and conclusions made by the subject. Questions were free or demographic inequality and enabled that every subject understood their responsibility. These questions were the first 6 questions of the and are shown below:

1. Which variety of lettuce do you believe has the highest levels of nutrient concentration based on TASTE?

A. Variety 598

B. Variety 127

C. Variety 341

2. Which variety of lettuce do you believe has the lowest levels of nutrient concentration based on TASTE?

A. Variety 598

B. Variety 127

C. Variety 341

3. Which variety of lettuce do you believe has the highest levels of nutrient concentration based on APPEARANCE?

A. Variety 598

B. Variety 127

C. Variety 341

\section{Consumer Preference of Hydroponic Nutrient Concentrations}

One of the most important marketability factors is exact consumer preference. Although one variety of lettuce might have higher nutritional value, it might not be the most liked by a select group of consumers tested. The same variety codes were used in one closed ended question that controls observations of consumers that aligns with study variables. Those tested were again asked to use all sensory processing techniques to decide which one they would prefer eating on a regular basis. Results were collected and analyzed in the results.

Which lettuce variety do you prefer?
A. Variety 598
B. Variety 127
C. Variety 341

\section{Results}

After conducting a series of tests, the following results were obtained. Analysis of each objective were preformed independently, but contribute to the overall goal of producing a more effective hydroponic lettuce crop in hydroponics systems and markets.

\section{Effective System Dimension}

Within Table 5, the average harvesting length of Tub A was $24.58 \mathrm{~cm}$, compared to Tub B with $22.17 \mathrm{~cm}$, and Tub C with $18.37 \mathrm{~cm}$. The mass and linear density of every lettuce crop was recorded too. The data shows Tub A average mass was highest with $16.32 \mathrm{~g}$, then with Tub B with $7.49 \mathrm{~g}$, and Tub C with $3.81 \mathrm{~g}$. Linear density is an important calculation to make to understand the amount of mass per unit length. The linear density of Tub $\mathrm{C}$ was the greatest with a value of 4.82 , then Tub B with 3.28, and Tub A with 1.29 grams per centimeter. 
A Bartlett statistical analysis test identifying homogeneity of variances among variables determined the post-harvest measurement of mass in Table 6 resulted in a significant value of 0.0000215 . The value was deemed significant being below $* 0.05$ when compared to a null hypothesis. Thus allowing us to know that variances are equal in all samples. A Sharipo-Wilk calculation in Table 7 demonstrated another significant value of .0000002621 of mass measurements with normal distribution that would allow for a continued ANOVA test. An one-way ANOVA test in Table 8 was completed with variant samples. This tests the probability that when compared to a null hypothesis, that these results could be replicated in future growing trials. The data showed the tub mass results to be significant with a value of 0.0000335. Since significance was found in the data of the lettuce mass in different tubs, a Tukey test calculation was completed in Table 9 showing the greatest contrast between tubs B and C with the value furthest away from standard p-value resulting in 0.0000236 . Every growing system will show statistical differences between each other, this test determines the greatest statistical difference. The greatest contrast was between lettuce grown in Tub B and. C. Lettuces grown in Tub B and C mass can be compared to see which one has the greatest mass, which is lettuce grown in Tub A. This tub results through statistical analysis will results in better yields due to its size of system.

\section{Consumer Recognition of Nutrient Concentration}

When consumers were asked which lettuce sample had the highest concentration levels based on appearance $35.6 \%$ answered correctly that lettuce Variety 127 was the type. However, $44.4 \%$ selected variety 341 , which was grown in normal amounts of concentration, meaning they are unable to recognize the highest concentrated lettuce based on appearance. The data for the consumer recognizing the lowest concentration showed that $35.6 \%$ of consumers could recognize that variety 598 has the lowest compared to $31.1 \%$ for those who chose variety 127 incorrectly. As consumers tasted the lettuce varieties for the results show that around $40 \%$ of consumers selected variety 341 to be grown in the highest and lowest concentration levels. Overall, consumers preferred lettuce variety 217 TUB C, compared to Variety 598 with $28.9 \%$, and $33.3 \%$ of Variety 341 when using all sensory preference techniques.

\section{Spectrometry Recognition of Nutrient Concentration}

The Plant Tissue analysis data showed whether trace elements can recognize different concentration levels by comparing the three data points of different leveled systems for each element and identifying if TUB C Variety 127 shows the highest percentages or ppm values. In the macronutrients elements Phosphorus, Potassium, Magnesium, and Sulfur had TUB $C$ lettuce have the highest percentages of trace elements calculated in Durbin-Watson regression analysis. Magnesium had the greatest range starting with $0.05 \%$ in TUB A, $0.56 \%$ in TUB B, and with a $0.62 \%$ of magnesium in which the plant contained. In the Micronutrients trace elements Manganese, Zinc, and Boron showed TUB C Variety 127 lettuce with the highest values of ppm calculated in DW. Manganese had the greatest range of ppm values with 18ppm of lettuce grown in TUB A, 202ppm in TUB B, and $159.5 \mathrm{ppm}$ in TUB C.

\section{Consumer Preference}

When consumers were asked which lettuce sample had the highest concentration levels based on appearance $35.6 \%$ answered correctly that lettuce Variety 127 was the type. However, 44.4\% selected variety 341 , which was grown in normal amounts of concentration, meaning they are unable to recognize the highest concentrated lettuce based on appearance. 
Table 5: Table of Average Length, Mass, and Statistical Analysis of Post-Harvest Lettuce Measurements.

\begin{tabular}{|l|l|l|l|}
\hline & $\begin{array}{l}\text { Average } \\
\text { Length }\end{array}$ & Average Mass & Linear Density \\
\hline Tub A & $22.17 \mathrm{~cm}$ & $16.32 \mathrm{~g}$ & 1.29 \\
\hline Tub B & $24.58 \mathrm{~cm}$ & $7.49 \mathrm{~g}$ & 3.28 \\
\hline Tub C & $18.37 \mathrm{~cm}$ & $3.81 \mathrm{~g}$ & 4.82 \\
\hline
\end{tabular}

Table 6: Bartlett Test of homogeneity variances that will determine variable differences are great enough to perform an ANOVA calculation.

\begin{tabular}{|l|l|l|}
\hline Variances & Length by Tub & Mass by Tub \\
\hline k-squared & 0.79548 & 21.49 \\
\hline p-value & 0.6718 & 0.00002155 \\
\hline
\end{tabular}

Table 7: Wilk- Shaprio statistical calculation determining significance in test.

\begin{tabular}{|l|l|l|}
\hline Variances & Length p-value & Mass p-value \\
\hline w-value & 0.97478 & 0.81136 \\
\hline p-value & 0.2484 & 0.0000002621 \\
\hline
\end{tabular}

Table 8: One-way ANOVA testing for statistical significance in hydroponic Tubs.

\begin{tabular}{|l|l|l|l|l|}
\hline Response & Df & Sum Sq & F-value & $\operatorname{Pr}(>\mathrm{F})$ \\
\hline & & & & 0.0000 \\
Tubs & 2 & 488.5 & 12.41 & 335 \\
\hline
\end{tabular}

Table 9: Statistical analysis using a Tukey Test.

\begin{tabular}{|l|l|l|}
\hline Contrast & Estimate diff. & $\mathrm{p}=$ value \\
\hline B-A & -2.412281 & 0.4810058 \\
\hline C-A & -3.795238 & 0.1378675 \\
\hline C-B & -6.207519 & 0.0000236 \\
\hline
\end{tabular}




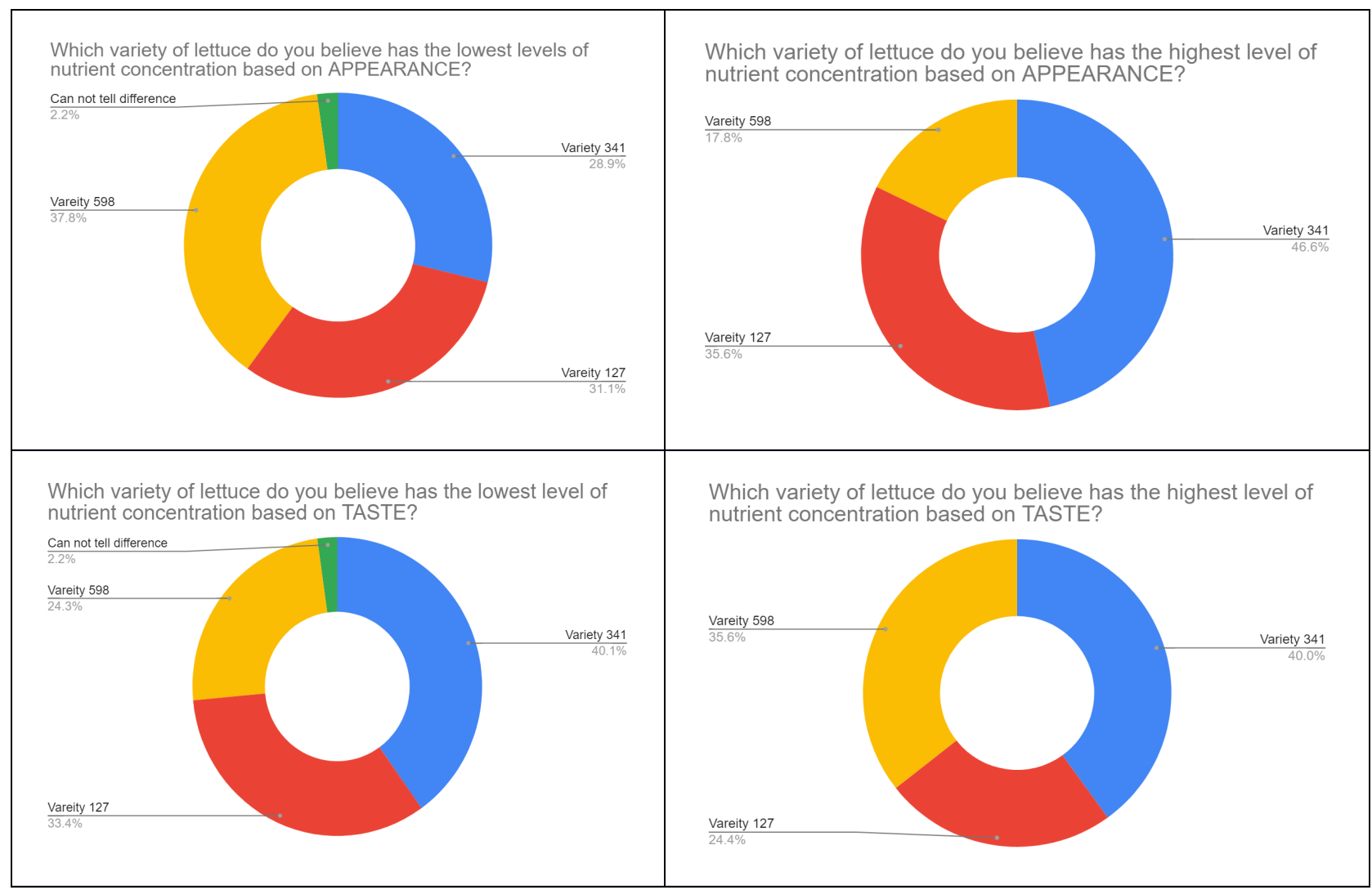

Figure 1. Population pie charts of consumer survey results

Table 10: Plant Tissue ICP-Spectrometry Averages of Macronutrient Element Concentration Percentages calculated through Durbin-Watson regression analysis calculations.

\begin{tabular}{|l|l|l|l|l|l|l|}
\hline \multicolumn{7}{|l}{ Plant Tissue Analysis Average Macronutrient Element Concentration Percentages } \\
\hline LAB\# SAMPLE\# & $\begin{array}{l}\text { (N) Nitro- } \\
\text { gen }\end{array}$ & (P) Phosphorus & (K) Potassium & $\begin{array}{l}\text { (Ca) Cal- } \\
\text { cium }\end{array}$ & (Mg) Magnesium & (S) Sulfur \\
\hline Variety 598 A & 6.22 & 1.02 & 10.21 & 2.03 & 0.05 & 0.31 \\
\hline Identification & HIGH & HIGH & HIGH & HIGH & NORMAL & $\begin{array}{l}\text { NORMA } \\
\text { L }\end{array}$ \\
\hline Variety 341 B & 6.16 & 1.09 & 10.16 & 1.51 & 0.56 & 0.3 \\
\hline Identification & HIGH & HIGH & HIGH & NORMAL & NORMAL & $\begin{array}{l}\text { NORMA } \\
\text { L }\end{array}$ \\
\hline Variety 127 C & 6.1 & 1.07 & 11.12 & 0.98 & 0.61 & 0.32 \\
\hline Identification & HIGH & HIGH & EXCESSIVE & NORMAL & NORMAL & $\begin{array}{l}\text { NORMA } \\
\text { L }\end{array}$ \\
\hline
\end{tabular}


Table 11: Plant Tissue ICP- Spectrometry Averages of Micronutrient Element Concentration in parts per million PPM.

\begin{tabular}{|l|l|l|l|l|l|l|}
\hline \multicolumn{2}{|l}{ Plant Tissue Analysis Average Micronutrient Element in PPM } \\
\hline LAB\# SAMPLE\# & $(\mathrm{Mn})$ Manganese & $(\mathrm{Cu})$ Copper & $(\mathrm{Zn})$ Zinc & $(\mathrm{Fe})$ Iron & $(\mathrm{B})$ Boron & (Na) Sodium \\
\hline Variety 598 A & 55.5 & 18 & 50.5 & 137.5 & 32 & 1265 \\
\hline Identification & LOW & NORMAL & NORMAL & NORMAL & NORMAL & NORMAL \\
\hline Variety 341 B & 202 & 10 & 39.5 & 174 & 36 & 1151 \\
\hline Identification & HIGH & NORMAL & NORMAL & NORMAL & NORMAL & NORMAL \\
\hline Variety 127 C & 159.5 & 12.5 & 75 & 127 & 47 & 703 \\
\hline Identification & NORMAL & NORMAL & NORMAL & NORMAL & NORMAL & NORMAL \\
\hline
\end{tabular}

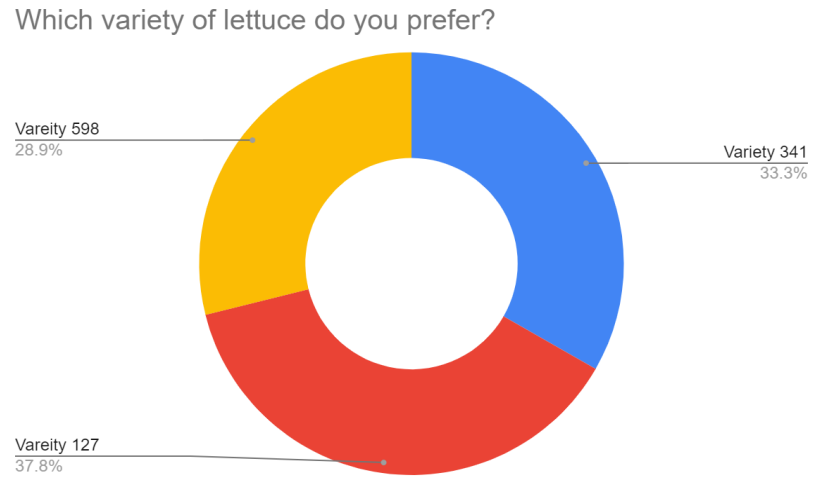

Figure 2: Pie chart of survey results on which lettuce variety was preferred.

\section{Discussion}

The analysis of the data shows that overall, consumers were unable to recognize different nutrient concentration levels by appearance and taste. Through the taste and visual recognition in Figure 1, results gave insufficient levels of success in peoples ability to identify correctly. Visually, only $35.6 \%$ were able to understand the correct highest nutrient plant, but people were able to identify the lowest nutrient level. With taste data having both of these questions having repeated data on the wrong answer helps identify the inability of consumers recognizing nutrient concentration of hydroponic lettuce. Generally, 37.8\% of consumers chose Variety 127 to be their overall preferred plant based on all sensory preference techniques.

Through the spectrometry plant tissue data obtained from Penn State Laboratories on the lettuce grown in three different nutrient concentrations showed that the data was able to recognize the differences through the trace element percentages. Seven of the twelve trace elements tested showed the highest percentages or ppm values in TUB $\mathrm{C}$, higher than the other tubs. This specific method of detection was chosen because looking at the individual trace 
elements percentages of each tub as the tubs get more concentrated allows researchers to understand the fluctuations and linear relationships leading up to the maximum concentration. Not all elements had clear linear relationships of increase of element presence. However, from the smallest percentages to the biggest percentages of the element shows significant growth. Understanding the values of elements present in a tissue sample also added more knowledge on proper nutrient amounts. Figures 3 and 4 give the standard percentages that lettuce crops should have in their system. The data samples express inconsistent in the manganese element, high rates in nitrogen, phosphorus, and manganese. Along with excessive rates of potassium. These quantitative identifications can be used in future research studies that will produce a more controlled research crop.

Significant concerns should be addressed when 5 elements did not show an increase in element presence and many of the elements having fluctuation values. Reasoning behind this idea can be inferred as being of something called "nutrient lockout", which is a plant slowing down the uptake of nutrients and water because of an excess of nutrients. The excess nutrients that are mineral salt based can be associated with concentrated TUB C.

With only plant analysis having the ability to identify plants grown in different nutrient concentration, further steps can be taken to promote yields and sales of farmers. Those growing to sell would now understand the advertising sensory difference between lettuce crops would not be effective. However, the data on concentration levels could be used to make further actions of certain trace nutrients elements in a water supply.

The analysis of the data shows that Tub B had the best growth and highest average length and mass when harvested. It can be concluded that Tub B would be the best to use for greatest yields due to it having the highest length and mass averages. Tub $\mathrm{C}$ would best to use for the greatest amount of mass per unit length or the plant leaf density. Tub B success can be applied to its flat and shallow system shape. The roots in the system are not able to grow directly down, but flow sideways. This motion and behavior of lettuce roots can be seen in the nutrient film technique system where the roots are meant to flow with the water.

With greatest contrast between lettuce grown in Tub B and C. Lettuces grown in Tub B and C mass can be compared to see which one has the greatest mass, which is lettuce grown in Tub A. This tub results through statistical analysis will results in better yields due to its size of system.

\section{Conclusion}

Through this test, it could be identified that plant tissue analysis recognition of lettuce crops grown in different nutrient levels is effective, with consumer recognition not showing success of identification. Along with a (102 x $50.8 \mathrm{x}$ $66 \mathrm{~cm}$ ) size deep-water culture system is produce lettuce with larger harvest-length. This information can be used to help small-scale hydroponic growers to increase efficiency of crops by knowing the proper growing methods. When farmers are able to make growing more successful and efficient, it betters the agricultural economy and the agricultural industry as a whole. Controlled environment agriculture (CEA) has an important future in every community to promote sustainability and equitable resources. Executing this study was another step in making controlled environment agriculture production greenhouse hydroponic growing more effective, cheaper, and efficient for farmers in the industry.

\section{Limitations}

The experimental trials of this study were not preformed to meet or sustain industry standards. Data collected and discussion provided is most applicable to small-scale greenhouse growers and small-business hobbyist. Further testing and trials must be conducted to imply effectiveness in production industry. Mass spectrometry was prepared and conducted in collaboration with Penn State University Agricultural Analytical Services Laboratory. This study was completed with out university advanced laboratory equipment; specially spectrometric analysis was not completed independently. 


\section{Acknowledgements}

I would like to thank Mrs. Courtney Bockbrader and Mrs. Whitney Short, Anthony Wayne Agri-science Educator Advisors, for their guidance and advising on the project. Thank you to Dr. John Nagle, Assistant Professor of Horticulture Sciences at Central State University, for answering questions about advanced hydroponics studies. And Rupp Seed Plant Breeder, Dr. Bill Holdsworth, for advice on and program use to run statistical analysis of the data and evaluate the results.

\section{References}

Barbosa, G. L., Gadelha, F. D., Kublik, N., Proctor, A., Reichelm, L., Weissinger, E., Halden, R. U. (2015, June 16). Comparison of Land, Water, and Energy Requirements of Lettuce Grown Using Hydroponic vs.

Conventional Agricultural Methods. Retrieved from https://www.ncbi.nlm.nih.gov/pmc/articles/PMC4483736/

Bartok, John. (2017, January 26). Hydroponic Systems. Retrieved from https://ag.umass.edu/greenhouse-floriculture/fact-sheets/hydroponic-systems

Fontana, L., Rossi, C. A., Hubinger, S. Z., Ferreira, M. D., Spoto, M. H., Sala, F. C., \& Verruma-Bernardi, M. R. (2018). Physicochemical characterization and sensory evaluation of lettuce cultivated in three growing systems.

Horticultura Brasileira, 36(1), 20-26. https://doi.org/10.1590/s0102-053620180104

Garza-Alonso, C.A.; Olivares-Sáenz, E.; Gutiérrez-Díez, A.; Vázquez-Alvarado, R.E.; López-Jiménez, A. Visual Symptoms, Vegetative Growth, and Mineral Concentration in Fig Tree (Ficus carica L.) Under Macronutrient Deficiencies. Agronomy. Retrieved from https://doi.org/10.3390/agronomy9120787\.

Gilmour, D. (2018). Consumers 'Willingness to Pay for Hydroponic Lettuce. Theses and Dissertations Retrieved from https://scholarworks.uark.edu/etd/2722

Harvard Business Review. (2015, February 17). The Science of Sensory Marketing Retrieved from https://hbr.org/2015/03/the-science-of-sensory-marketing

Huang, M. (2018). Market Analysis of Hydroponic Lettuce in the Nashville Region. School of Environment, Nanjing University. Retrieved from http://citeseerx.ist.psu.edu 
Roberts, O. (2019, August 01). Food safety handbook for hydroponic lettuce production in a deep water culture. Retrieved January 31, 2021, from https://ecommons.cornell.edu/handle/1813/69355.

Röll, G.; Hartung, J.; Graeff-Hönninger, S. Determination of Plant Nitrogen Content in Wheat Plants via Spectral Reflectance Measurements: Impact of Leaf Number and Leaf Position Remote Sens. 11, no. 23: 2794. https://doi.org/10.3390/rs11232794.

Sardare, Mamta. (2013). A REVIEW ON PLANT WITHOUT SOIL - HYDROPONICS. International Journal of Research in Engineering and Technology. Retrieved from http://citeseerx.ist.psu.edu/viewdoc/summary?doi=10.1.1.677.1105

White, Bridget. (2004). Alternative Hydroponic Substrates. Retrieved from https://gpnmag.com/article/alternative-hydroponic-substrates/. 